\title{
"Escola em quarentena": um projeto de registro antropológico de memórias educacionais durante a pandemia da Covid-19
}

\section{School in quarantine: a project for the anthropological archive of educational memories during the covid-19 pandemic}

\author{
Juliane Bazzo ${ }^{1}$, Kelli Schmiguel ${ }^{2}$, Roselaine Lucena Suarez ${ }^{3}$ \\ ${ }^{1}$ Universidade Federal da Grande Dourados (UFGD), Dourados, Mato Grosso do Sul, Brasil. ORCID: https://orcid.org/0000-0001-6196-3482 \\ 2 Secretaria de Educação do Estado do Ceará, Fortaleza, Ceará, Brasil. Universidade da Integração Internacional da Lusofonia Afro-Brasileira (UNILAB), \\ Redenção, Ceará, Brasil. ORCID: https://orcid.org/0000-0002-9102-9866 \\ ${ }^{3}$ Cia OBaobá, Curitiba, Paraná, Brasil. ORCID: https://orcid.org/0000-0003-2750-9184
}

Autor para correspondência/Mail to: Juliane Bazzo, bazzojuliane@gmail.com

Recebido/Submitted: 03 de setembro de 2020; Aceito/Approved: 28 de outubro de 2020

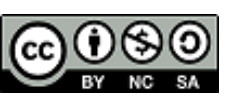

\begin{abstract}
Copyright (C) 2020 Bazzo, Schmiguel, \& Suarez. Todo o conteúdo da Revista (incluindo-se instruções, política editorial e modelos) está sob uma licença Creative Commons Atribuição-NãoComercial-Compartilhalgual 3.0 Não Adaptada. Ao serem publicados por esta Revista, os artigos são de livre uso em ambientes educacionais, de pesquisa e não comerciais, com atribuição de autoria obrigatória. Mais informações em
\end{abstract} http://revistas.ufpr.br/atoz/about/submissions\#copyrightNotice.

\begin{abstract}
Resumo
Introdução: o paper realiza um relato de experiência acerca do projeto "Escola em quarentena: um registro antropológico de memórias educacionais", originado em abril de 2020 e hospedado em uma plataforma virtual. A iniciativa tem por intuito fomentar o aprendizado social, a gestão do conhecimento, bem como a ciência aberta e cidadã durante o período de ensino remoto emergencial no Brasil, diante da pandemia da Covid-19. Metodologia: o projeto operacionaliza-se pautado por uma inspiração etnográfica, que advém de suas origens calcadas na Antropologia da Educação enquanto subcampo disciplinar. Resultados: a iniciativa alcançou a marca de quinhentos participantes e já gerou mais de uma centena de conteúdos compartilhados. Além disso, vem alcançando repercussões na mídia. Conclusão: a expectativa é que o projeto seja continuado enquanto se estender a educação remota emergencial. Para além disso, no futuro, espera-se que as fronteiras virtuais sejam ultrapassadas, no intuito de democratizar o conhecimento acumulado sob outros formatos.
\end{abstract}

Palavras-chave: Covid-19; Pandemia; Educação remota; Memória educacional; Aprendizado social; Ciência aberta.

\begin{abstract}
Introduction: the paper presents an experience report about the project "School in quarantine: an anthropological archive of educational memories", originated in April 2020 and hosted on a virtual platform. This initiative has the aim of promoting social learning, the management of knowledge, as well as open and citizen science, during the period of the emergency remote teaching in Brazil, in the face of the Covid-19 pandemic.

Method: the project is operationalized based on an ethnographic inspiration, which comes from its origins in the Anthropology of Education as a disciplinary subfield. Results: the initiative reached the mark of five hundred participants and has already generated more than a hundred shared contents. Also, it has achieved repercussions in the media. Conclusions: the expectation is that the project will be continued as long as the emergency remote education. Furthermore, in the future, it is expected that the virtual boundaries will be crossed to democratize the knowledge accumulated in other formats.
\end{abstract}

Keywords: Covid-19; Pandemic; Remote education; Educational memory; Social learning; Open science.

\section{INTRODUÇÃO}

A pandemia da Covid-19 repercutiu globalmente sobre todos os setores da vida neste ano de 2020 e seus integrais impactos ainda serão determinados. Algumas áreas, contudo, sentiram de modo ainda mais brusco e imediato os efeitos da ágil dispersão do novo coronavírus. Dentre elas, certamente, está a educação, que precisou suspender rapidamente, nos diversos níveis de ensino formal, as atividades presenciais, em virtude da alta probabilidade de contágio em ambientes marcados por aglomerados de pessoas. Em tempo recorde, docentes, técnicas educacionais, estudantes e suas famílias se viram, ao redor do mundo, envolvidos em novos experimentos de aprendizagem, de caráter remoto emergencial.

Diante do inesperado desse contexto, a ciência foi outro nicho instantaneamente tocado e convocado a buscar medidas de enfrentamento a uma crise multifacetada, ao mesmo tempo sanitária, geopolítica, econômica e sociológica. Desde a identificação da doença em fins de 2019 na China, mas especialmente a partir da decretação de sua natureza pandêmica pela Organização Mundial de Saúde (OMS) nos primeiros meses do ano seguinte, o volume de pesquisas, nas mais diversas frentes, evoluiu avassaladoramente em todo o planeta (World Health Organization, 2020).

Para tanto, mostrou-se necessário repensar o próprio modo de conduzir essas investigações, de maneira a assegurar, o mais rigorosamente possível, o distanciamento social exigido perante uma mazela infecciosa ainda 
sem remédio ou vacina desenvolvidos. Nesse decurso, migraram em peso para plataformas digitais os estudos das ciências naturais e humanas que envolvem pessoas como sujeitos de pesquisa, sob uma miríade de temas. E, entre seus instrumentos de pesquisa mais recorrentes, observou-se a difusão, nas redes sociais virtuais, de questionários fechados ou abertos, gerenciados sob apoio de ferramentas como o Google Forms.

Originado em abril de 2020, o projeto "Escola em quarentena: um registro antropológico de memórias educacionais" situa-se como fruto desse movimento massivo, embora sua inspiração metodológica advenha do modo etnográfico de produzir conhecimento, típico da Antropologia enquanto campo do saber. Uma etnografia, para se constituir, pode contemplar a aplicação de perguntas como aquelas reunidas em questionários, mas não se restringe a isso: inclui também a observação sistemática, a escuta atenta, bem como interlocuções mais fluidas e contingentes com os sujeitos de pesquisa, estejam off-line ou on-line (Miller, 2020).

O "Escola em quarentena" almeja reunir, em um espaço compartilhado, relatos que não cessam de se avolumar na internet, assinados por docentes, técnicas educacionais, estudantes e seus familiares, acerca de dilemas, adaptações e aspirações, na tarefa de ensinar e aprender nesse momento que foge completamente ao ordinário. No que tange à realidade do Brasil, na qual se baseia o projeto, tais falas tomam forma a partir de contextos de vida bastante diversificados. Essas vozes ecoam redes de ensino públicas e privadas, de diferentes regiões geográficas, que retratam um país plural, mas também muito desigual socioeconomicamente, perante a empreitada de lidar com a educação remota emergencial.

Mesmo em meio a um dia a dia turbulento, os sujeitos das comunidades escolares têm conseguido, portanto, encontrar tempo para ofertar minuciosas impressões, que certamente merecem ser preservadas e potencializadas enquanto memória e conhecimento. Logo, o objetivo do "Escola em quarentena" reside em justamente auxiliar o encontro dessas narrativas num mesmo lugar, para refletir sobre os desafios do presente e, também, angariar elementos para imaginar coletivamente um futuro pós-pandemia à educação brasileira.

Para isso, o projeto delimitou, como seu espaço de funcionamento, um grupo de aprendizado social na rede Facebook (Escola em quarentena: um registro antropológico de memórias educacionais). (2020), o qual conta atualmente com cinco centenas de membros. A iniciativa nasce vinculada ao blog de divulgação científica Primavera nos dentes - Ensaios sobre a escola e a realidade brasileira. (2020), gerenciado de modo independente pela primeira autora deste paper. O blog tem por missão visibilizar e enriquecer debates em Antropologia da Educação, enquanto um subcampo disciplinar em expansão (Bazzo, 2020a).

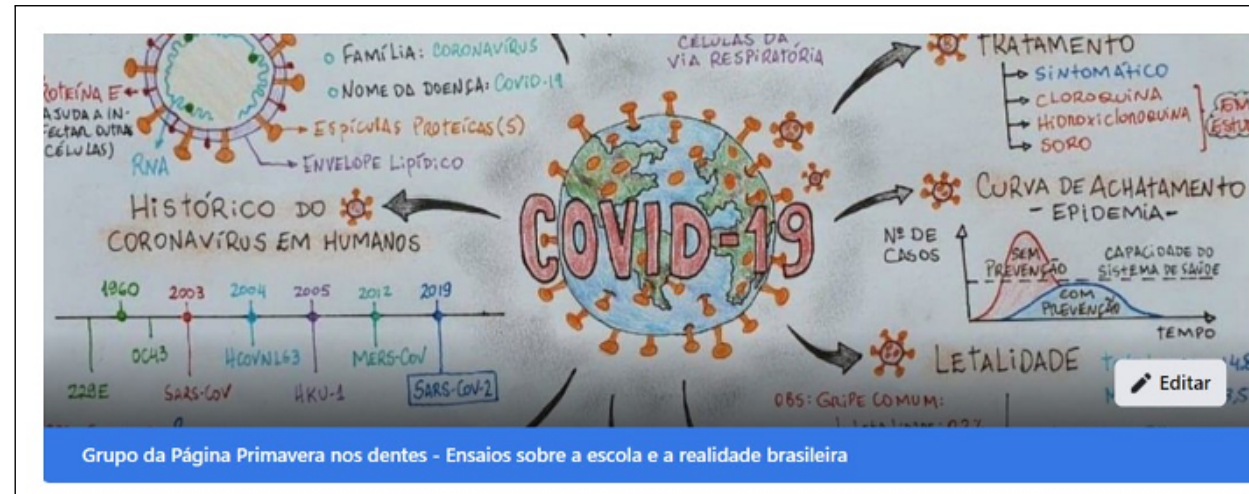

\section{Escola em quarentena: um registro antropológico de memórias educacionais \\ @ Grupo Privado 507 membros}

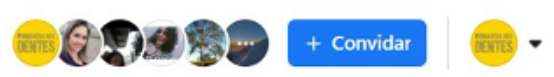

https://www.facebook.com/groups/escolaemquarentena

Figura 1. Página principal do projeto "Escola em quarentena”. Fonte: Elaborado pelas autoras (2020).

O "Escola em quarentena", por conseguinte, valoriza a interdisciplinaridade entre a Educação e a Antropologia, intrínseca às suas origens, como também ao background acadêmico-profissional de sua coordenação tripartite, realizada pelas autoras do presente texto. Além disso, têm-se em tela um projeto que lança mão das redes sociais virtuais para realizar a gestão do conhecimento e a aprendizagem coletiva. Por fim, trata-se de um esforço de promoção da ciência aberta e cidadã, ao partilhar dados qualitativos de pesquisa no compasso em que estes vão sendo gerados, via engajamento das e dos agentes das comunidades escolares no projeto.

Ao longo deste paper, dar-se-á privilégio à marcação feminina de gênero, que guarda maior consonância com o 
público abarcado pela iniciativa aqui descrita, como adiante se explicará.

\section{PROCEDIMENTOS METODOLÓGICOS E RESULTADOS}

Conforme mencionado, a operacionalização metodológica do projeto "Escola em quarentena" seguiu um caminho díspar em relação a um volume considerável de pesquisas on-line que, no cenário de dispersão do novo coronavírus, vêm se pautando pela aplicação de questionários estruturados. A iniciativa de viés etnográfico em vitrine aqui, por sua vez, replicou com adaptações o modelo do estudo "Relatos do cotidiano durante a pandemia", coordenado pelos sociólogos Paulo Gajanigo (Universidade Federal Fluminense - UFF) e Rogério Souza (Universidade Candido Mendes - UCAM).

Sob o propósito de construir um arquivo da vida ordinária durante a quarentena e, assim, auxiliar na perenização da memória social brasileira desse momento, a investigação da referida dupla se desenrola em um grupo de aprendizado social na rede Facebook (Relatos do cotidiano durante a pandemia). (2020). Esse ambiente estruturase por unidades de trabalho, que acomodam especialmente depoimentos sobre o dia a dia, mas também descrições de sonhos, expressões artísticas e um inventário de transformações na mobília doméstica, todos conteúdos compartilhados pelos participantes do grupo, desde março de 2020, quando foi decretada a emergência sanitária (Gajanigo \& Souza, 2020).

O "Escola em quarentena", igualmente, organiza-se até o momento a partir de três unidades de trabalho, adequadas aos seus propósitos específicos: (a) "Narrativas originais", que agrega relatos enviados exclusivamente ao grupo por suas membras a respeito do cotidiano educacional diante da pandemia; (b) "Narrativas viralizadas", que abrange conteúdos com esse mesmo perfil em alta circulação nas redes sociais virtuais e, portanto, de interesse das participantes; (c) "Narrativas provocadas", que contemplam enquetes dirigidas em torno de assuntos com potência de debate, afeitos ao escopo do projeto.

Qualquer pessoa com uma conta no Facebook pode demandar acesso ao grupo, que se dá sob aceite da moderação. Para participar, as membras devem acatar um conjunto condensado de regras éticas. Estas incluem o compartilhamento de narrativas mediante aprovação da administração do grupo, como também o aceite tácito de sua publicidade, tanto nesse ambiente, quanto em outros desdobramentos que o projeto venha a ter, estejam os relatos em forma escrita, visual ou audiovisual. O formato das narrativas é totalmente livre, mas se solicita a indicação de alguns dados sobre cada autora, como a cidade onde vive, a função desempenhada em sua comunidade escolar e a informação sobre vínculo a uma rede de ensino pública ou privada. Todavia, caso manifestado o desejo, são aceitos também relatos sob anonimato.

À época da escrita deste paper, o projeto reunia 50 narrativas originais, 65 narrativas viralizadas e quatro narrativas provocadas. A princípio, a moderação do grupo optou por compartilhar tais relatos com comentários desativados, orientada pela aspiração primeira de promover a circulação dessas vozes. Entretanto, com a inauguração da unidade de narrativas provocadas, passou-se a abrir a possibilidade de comentários das membras nas enquetes, a fim de enriquecer a discussão proposta. Em seguida, tanto narrativas originais, quanto viralizadas, passaram a ser selecionadas para permanecer com comentários abertos, a fim de fomentar debates guiados anunciados em posts específicos pela administração do grupo, no esforço de tornar a troca de ideias a mais produtiva possível. Atesta-se a eficácia desse procedimento pela ausência de qualquer episódio de desacato no interior do ambiente virtual em questão.

Quanto às temáticas abarcadas pelas narrativas, pode-se sintetizar que contemplam uma série de dificuldades de adaptação ao ensino remoto, tanto de estudantes e seus familiares, como de docentes e técnicas, seja no que diz respeito ao manejo da tecnologia, à reformulação de conteúdos a distância, à criação de vínculos afetivos via plataformas ou ainda ao equilíbrio com as rotinas domésticas e também profissionais dos adultos. Não obstante, chegam também relatos que revelam como tais personagens estão procurando lidar ou contornar esses obstáculos no dia a dia, com maior ou menor sucesso, por se tratar de um cenário excepcional. As figuras a seguir reúnem exemplos relativos a essas questões. 
Unidade 1 - Narrativas originais

\section{Narrativa 12}

Colo aqui mais um desabafo:

Usar o uniforme escolar em casa

Ontem a escola que Arthur ( 7 anos) estuda (particular) resolveu mandar um video com diretores-donos passando um recado sobre os próximos passos. Queriam um retorno das aulas presenciais mas o Governo do Estado não permitiu. Óbvio, a escola é particular, mas o problema da Covid è de saúde pública.

A dona da escola em tom pesado deu orientaçōes de disciplina, controle das crianças e cobrou o uso do uniforme mesmo dentro de casa para as aulas virtuais.

Uniforme vem de "uma única forma", de farda. A nomenclatura fol inventada no século XV por instituiç̃es militares. No Brasill o uso de uniformes escolares começou no Rio de Janeiro no século XIX. A ideia era não mostrar diferenças entre ricos e pobres, mas acabou sendo um bom artificio de maquiar as desigualdades. É visto em estudos que por traz de um uniforme existe uma mensagem subliminar na vestimenta onde se reclama do aluno um porte exemplar, zelando assim pela imagem da instituiçăo.

Uniforme na escola até se acha justificativas plausiveis, mas em casa nâo. Uniforme tira identidade, tira particularidade. Uniforme padroniza, deixa todos com cara de "carne moida" (ver o clipe novo Another Brick in the Wat do Pink Floyd de 1979 para entender meu "carne moida).

Não vai ter "carne moída" aqui, nem hoje, nem amanha, nem semana que vem.
Narrativa 16

Aula suspensa em prol do ber

Aula online e pra quem pode

Na quebrada tem aluno que nem internet tem

Eal eu pergunto: Essa decisão favorece a quem?

Narrativa 36

RELATO PESSOAL - sobre as aulas on-line e os professores EAD do momento:

Gostaria de falar, como professora, que não estávamos preparados para esta situaçăo EAD e lamento as tantas criticas ouvidas (de pais e
pessoas que interagem com a educaçào). De uma hora para outra, temos de ser apresentadores de TV e animadores de plateia? Ser professor demanda uma intensa interaçăo pessoal, emocional e física e disso sabemos bem, mas a distáncia a nós obrigada apresentou-nos

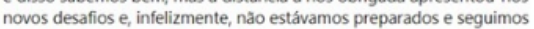
aprendendo este novo lugar. Aliás, muitos dos professores que estão nas TVs nåo fizeram um curso antes de começarem a gravar e nem tinham orientaçōes tão precisas sobre como gravar porque o sistem educacional realmente năo estava preparado para isso. Temos formaçåo no presencial e nåo EAD. Alguns professores inclusive sequer tinham estado em frente a uma câmera sequer interagindo com a famnlia. Mas muitos precisam gravar suas aulas para que as crianças e adolescentes não fiquem sem conteúdo. Sei que há muito para melhorar e poderia ser melhor este sistema educacional, mas muita cente envolvida no processo educacional năo estava pronta para essa mudança e este novo estado. Sim, a escola demora para mudar a gente sabe e nao eculpa so dela tambem. Assim, neste me psimera situra, de a pouc a empatia para com os professores ques estào gravando aulas.

Figura 2. Exemplos de 'Narrativas originais'.

Fonte: Elaborado pelas autoras (2020).

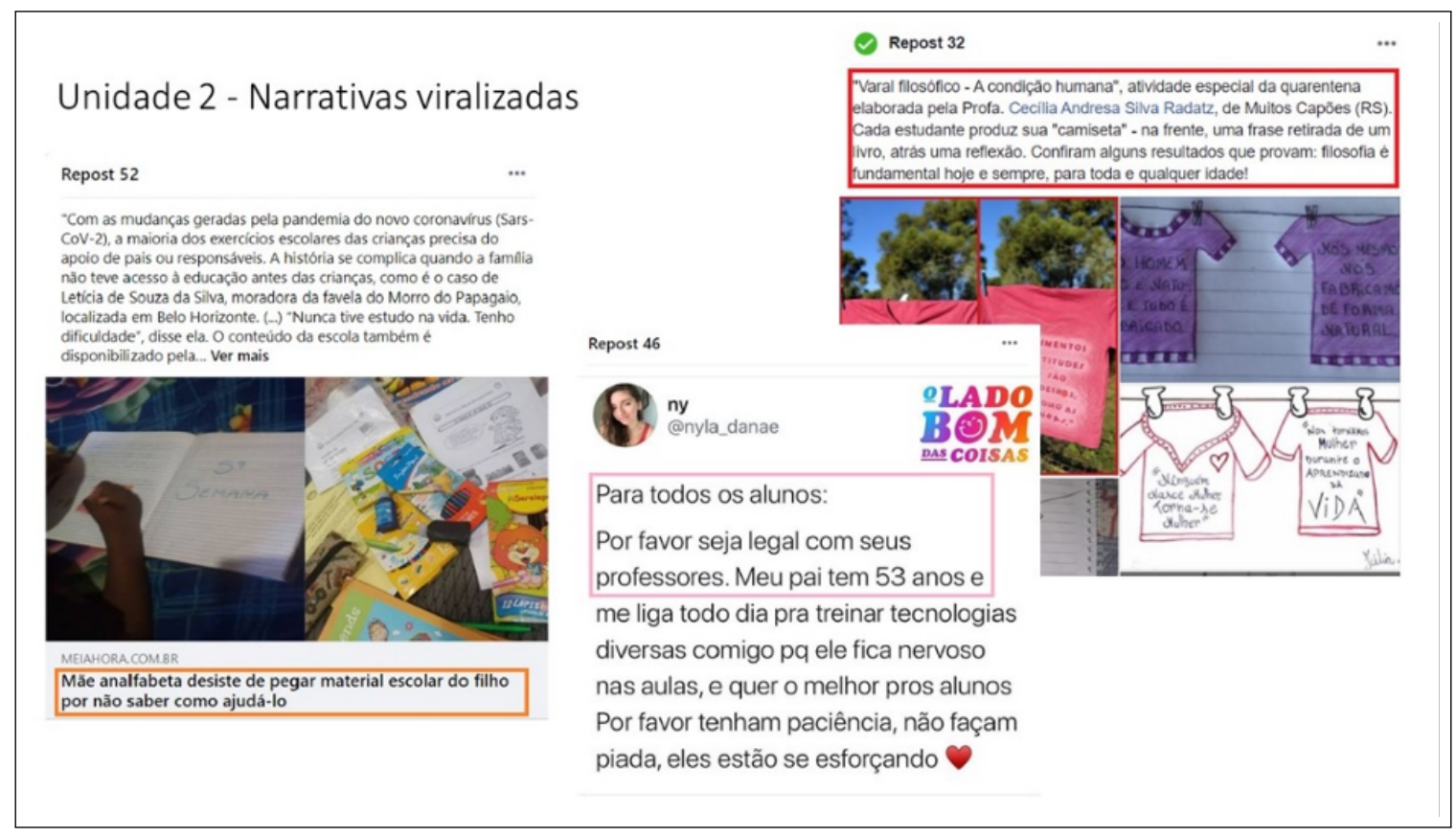

Figura 3. Exemplos de 'Narrativas viralizadas'.

Fonte: Elaborado pelas autoras (2020). 


\section{Unidade 3 - Narrativas provocadas}

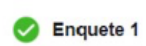

o Escola em quarentena inicia uma nova unidade de aprendizado social, que vai reunir 'narrativas provocadas'. Funcionará assim: uma enquete será lançada para as/os participantes do grupo, com algumas opçöes de resposta. Cada pessoa poderá selecionar quantas quiser e, na sequência, ofertar suas impressōes sobre a questāo nos comentários, que agora estarão abertos. Bora deixar a timidez de lado e compartilhar reflexões? $\mathbf{E}$ a unidade já começa com uma pergunta pra lá de polêmica:

VOCÉ ACHA QUE ESSE ANO LETIVO DEVERIA SER ANULADO?

Sim - por quê? Conte mais nos comentários! Adcicolacoro por Primavera nos dentes - Ensaios sobre a Não - por quê? Conte mais nos comentários! Adicionaclo por Primavera nos dentes - Ensaios sobre a

Estou em dúvida - por quê? Conte mais nos comentários!

\section{(c)}

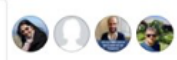

(2)
Enquete 2

Atençăo, atençăo: nova enquete no ar! A receptividade foi ottima e as reflexões muito produtivas, então, prosseguimos com nossa unidade de narrativas provocadas. A questão agora é:

COMO VOCÉ IMAGINA A ESCOLA IDEAL NO FUTURO PÓS-

PANDEMIA?

Relembrando: é possivel selecionar mais de uma opção. E năo Relembre coin possiel selec persam a respeito

Figura 4. Exemplos de 'Narrativas provocadas'.

Fonte: Elaborado pelas autoras (2020).

A fim de sistematizar as narrativas em trânsito, houve o delineamento de tópicos classificatórios, ordenados pelos papéis das participantes em suas comunidades escolares. Com isso, constata-se que a maior parte das narrativas possui, até o momento, a assinatura de mães com filhos em escolas públicas (três dezenas dos relatos reunidos). Em seguida, aparecem as professoras de escolas públicas (duas dezenas) e as mães com crianças no ensino privado (uma dezena). Percebe-se, assim, uma característica distintiva do conjunto de participantes: as mulheres constituem $80 \%$ desse universo. Quanto à localização geográfica, informada pelo gerenciamento de informações do próprio Facebook, cerca de $50 \%$ das membras do grupo estão no Sul do Brasil; adiante, vem a região Sudeste, com aproximadamente $10 \%$.

Tais dados expõem desigualdades de gênero, de classe e, muito provavelmente, de raça, que se mostram deveras profundas na realidade brasileira e, não raro, operam de modo interseccional (Crenshaw, 2002; Souza, 2009). A esmagadora participação feminina no projeto dá comprovação de que, em uma sociedade como a nossa, de origens escravocratas e afinada ao patriarcado ocidental, o cuidado de crianças recai maciça e iniquamente sobre as mulheres, principalmente às mais empobrecidas e, entre estas, às mulheres negras (Bazzo, 2020c). Por seu turno, o fato de a maior parte das membras residir nas regiões Sul e Sudeste, as duas mais ricas do país, evidencia disparidades socioeconômicas na geografia, as quais se espelham em índices de inclusão digital, considerados nesse domínio tanto o acesso pleno às tecnologias da informação e comunicação, quanto o necessário letramento para delas usufruir (Spyer, 2017).

Dessa maneira, embora seja emblemático, no "Escola em quarentena", o volume de narrativas oriundas da rede pública de ensino, tem-se claro que uma considerável fatia de vivências de segmentos mais desfavorecidos da população brasileira, especialmente das regiões geográficas menos abonadas, não está sendo devidamente captada pela iniciativa. Essa é, sem dúvida, uma reverberação de um problema grave nesse momento de educação remota emergencial: diante da suspensão das atividades presenciais, muitas famílias se encontram em severas dificuldades para continuar nutrindo vínculos com suas comunidades escolares, as quais constituem elos fundamentais na corrente de proteção social (Parreiras \& Macedo, 2020).

Uma forma de contornar tal lacuna tem sido a indicação de conteúdos a esse respeito no grupo, na unidade de narrativas viralizadas. Um exemplo residiu na chamada para que as membras conhecessem o Blog Lugar de criança é:? (2020). Nesse espaço, vêm sendo reunidos relatos de crianças e familiares em situação de vulnerabilidade social, assim como de trabalhadores de assistência nesse campo, especialmente residentes na região costeira paranaense, acerca do período de aulas remotas com a pandemia. A coleta dos dados difundidos pelo blog viabiliza-se por redes tecidas, anteriormente à emergência sanitária, pelo projeto "Territórios urbanos e oferta de programações esportivas", vinculado ao Campus Litoral da Universidade Federal do Paraná (UFPR) e encabeçado por Eduardo Thomassim e Marisete Hoffmann, docentes da instituição.

\section{CONCLUSÕES}

O "Escola em quarentena" vem sendo objeto de atenção em entrevistas na mídia, artigos de divulgação científica e comunicações em eventos (Bazzo, 2020b, 2020d; Bazzo, Schmiguel, \& Suarez, 2020). No grupo, há um tópico 
classificatório chamado "Repercussões do projeto", em que a equipe está reunindo tais reverberações.

A iniciativa deve continuar sua atividade enquanto perdurar a educação remota emergencial. Para além disso, espera-se que possa alcançar desdobramentos que superem as fronteiras virtuais. Nesse sentido, a equipe responsável vem refletindo sobre quais seriam os melhores meios de democratizar esse aprendizado coletivo na forma de conhecimento educacional. O certo é que frentes de ensino, pesquisa e extensão serão exploradas, nas quais todas as administradoras do projeto estão mais ou menos diretamente envolvidas.

Contudo, independentemente de quaisquer desdobramentos, considera-se que o projeto desde agora já presta um serviço à memória. Se refletimos com autores como Pollak (1898), sabemos que toda e qualquer memória não é dada, mas sim elaborada por um intenso jogo social de forças, capaz de projetar certas lembranças em detrimento de outras, com efeitos muito concretos sobre a realidade e o destino das pessoas. O "Escola em quarentena" delimita, assim, um mosaico de percepções dos agentes das comunidades escolares, conferindo uma espécie de perenidade, dentre outras possíveis, aos seus anseios, afetos e devires, perante a pandemia como um evento certamente divisor de águas neste século. 


\section{REFERÊNCIAS}

Bazzo, J. (2020a). Escola em quarentena: novos desafios, velhos dilemas. [blog]. Recuperado em 2020, abril 22, de https://confinaria.hypotheses.org/744.

Bazzo, J. (2020b). Escola em quarentena: um registro antropológico de memórias educacionais. In Vii cirkula do ppga/ufpe: O fazer antropológico em tempos de pandemia. Recuperado de https://youtu.be/2oDdPCnycyA?list= PLobe-LHB675-rntnjUaTuKaRzNBY07e3U.

Bazzo, J. (2020c). Não tenho filhos. posso ser aliada da maternidade? Catarinas. Recuperado de https://catarinas info/nao-tenho-filhos-posso-ser-aliada-da-maternidade/.

Bazzo, J. (2020d). O amanhã no "chão da escola": lidando com afetos. Le Monde Diplomatique. Recuperado de https://diplomatique.org.br/o-amanha-no-chao-da-escola -lidando-com-afetos/.

Bazzo, J., Schmiguel, K., \& Suarez, R. L. (2020). Projeto escola em quarentena [facebook]. Recuperado de https:// m.facebook.com/watch/?v=2810026785786509\& rdr.

Blog lugar de criança é:?? (2020). Recuperado de https:// lugardecriancaufprlitoral.blogspot.com.

Crenshaw, K. (2002). Documento para o encontro de especialistas em aspectos da discriminação racial relativos ao gênero. Revista Estudos Feministas, 10(1), 171-188. doi: 10.1590/S0104-026X2002000100011.

Facebook (escola em quarentena: um registro antropológico de memórias educacionais). (2020). Recuperado de https:// www.facebook.com/groups/escolaemquarentena.

Facebook (relatos do cotidiano durante a pandemia). (2020). Recuperado de https://www.facebook.com/groups/ $2261561834146786 /$.

Gajanigo, P., \& Souza, R. (2020). Registros do cotidiano durante a pandemia de covid-19: um relato de pesquisa. $R e$ vista Discente Planície Científica, 2(1), 10-22. Recuperado de https://periodicos.uff.br/planiciecientifica/article/view/ 43344 .

Miller, D. (2020). Notas sobre a pandemia: como conduzir uma etnografia durante o isolamento social. [blog]. Recuperado em 2020, maio 23, de https://blogdolabemus.com/ 2020/05/23/notas-sobre-a-pandemia-como-conduzir-uma -etnografia-durante-o-isolamento-social-por-daniel-miller/.

Parreiras, C., \& Macedo, R. M. (2020). Desigualdades digitais e educação: breves inquietações pandêmicas. Boletim Cientístas Sociais(36). Recuperado de http://www.anpocs.com/index.php/ publicacoes-sp-2056165036/boletim-cientistas-sociais /

2350-boletim-n-36-cientistas-sociais-e-o-coronavirus.

Pollak, M. (1898). Memória, esquecimento e silêncio. Estudos Históricos, 2(3), 3-15. Recuperado de http://www.uel.br/cch/cdph/arqtxt/Memoria _esquecimento_silencio.pdf.

Primavera nos dentes - ensaios sobre a escola e a realidade brasileira. (2020). Recuperado de https:// blogprimaveranosdentes.wordpress.com/.

Souza, J. (2009). Ralé brasileira: quem é e como vive. Belo Horizonte: Editora da UFMG.

Spyer, J. (2017). Social media in emergent brazil. Londres: UCLPress.

World Health Organization. (2020). Global research on coronavirus disease (covid-19). Recuperado em
2020, outubro 19, de https://www.who.int/emergencies/ diseases/novel-coronavirus-2019/global-research-on-novel -coronavirus-2019-ncov
Bazzo, J., Schmiguel, K. \& Suarez, R. L. (2020). "Escola em quarentena": uma projeto de registro antropológico de memórias educacionais durante a pandemia da Covid-19. AtoZ: novas práticas em informação e conhecimento, 9(2), 234 - 240. Recuperado de: http://dx.doi.org/10.5380/atoz.v9i2.76279 